Letrônica, Porto Alegre, v. 7, n. 1, p. 278-297, jan./jun., 2014

\title{
A INFLUÊNCIA DOS ANTECEDENTES DISPONÍVEIS E NÃO-DISPONÍVEIS NO PROCESSAMENTO DA ANÁFORA “ELE(A) MESMO(A)” EM PORTUGUÊS BRASILEIRO (PB)
}

\author{
THE INFLUENCE OF BOTH AVALIABLE AND NOT AVALIABLE \\ ANTECEDENTS IN THE PROCESSING OF ANAPHORIC ELEMENT \\ “ELE(A) MESMO(A)” IN BRAZILIAN PORTUGUESE (PB)
}

\author{
Rosana Costa de Oliveira* \\ José Ferrari Neto* \\ Janaina Barros Castor ${ }^{* * *}$
}

\begin{abstract}
Resumo: Nesta pesquisa, investigamos o processamento das relações correferenciais do português brasileiro (PB) com o objetivo de compreender como esse processo se desenvolve na mente dos falantes dessa língua. Buscamos compreender como os Princípios A e B da Teoria da Ligação (Binding Theory, CHOMSKY, 1986) atuam na interpretação das anáforas correferenciais em sentenças com pronome reflexivo. Utilizando a técnica de leitura automonitorada, replicamos o trabalho aplicado por Oliveira et al. (2012), que investiga a influência dos antecedentes disponíveis e não disponíveis no processamento da anáfora "a si mesmo(a)", substituindo apenas seu termo anafórico, "a si mesmo(a)", por "ele(a) mesmo(a)". Neste caso, dividimos "ele(a) mesmo(a)" em dois segmentos, com o intuito de verificar se o processamento do primeiro segmento será afetado pelo Princípio B, ou seja, se "ele(a)" irá se vincular ao antecedente fora do domínio de escopo da anáfora, ou, ao chegar ao segmento seguinte "mesmo(a)" haveria uma reanálise de sua decisão inicial a partir de um processo interpretativo que forçaria a aplicação do Princípio A. Os resultados encontrados corroboram o estudo feito em inglês por Nicol e Swinney (1989), assim como vão na mesma direção dos resultados obtidos por Oliveira, Leitão e Henrique (2012) para o português. Em ambos os trabalhos, a anáfora estabelece relação com o antecedente disponível, ou seja, o mais próximo em termos da Teoria da Ligação.
\end{abstract}

Palavras-chave: Teoria da Ligação; Processamento Correferencial; Anáforas.

\begin{abstract}
In this article, we investigated the processing of coreferential relations in Brazilian Portuguese (BP) to understand how this process develops in the human mind. The goal was to investigate how Principle A and Principle B of the Binding Theory (CHOMSKY, 1986) operate in the interpretation of coreferential anaphoric elements in sentences with reflexive pronouns. Using a self-paced reading paradigm, we replicated an experiment carried out by Oliveira et al. (2012), which investigated the influence of available and unavailable antecedents in the processing of the anaphoric element "a si mesmo(a)." In the present experiment, we only replaced the anaphoric word "a si" by "ele(a)." The goal was to investigate if the processing of the first element will be affected by Principle B or A. In the
\end{abstract}

\footnotetext{
${ }^{*}$ Professora Adjunta do Programa da Pós-Graduação em Linguística da Universidade Federal da Paraíba (UFPB).

${ }^{* *}$ Professor Adjunto do Programa da Pós-Graduação em Linguística da UFPB.

*** Aluna de Graduação em Letras da UFPB.
} 
first case, if the pronoun "ele" is be bound to an antecedent out of the anaphora's scope; in the second case, if the domain or if the following segment "mesmo(a)" is processed, there would be a reassessment of the initial decision from the interpretative process that forces application of Principle A. The results corroborate Nicol and Swinney's (1989) study, and Oliveira, Leitão and Henrique's (2012) study about Brazilian Portuguese. In both studies, the anaphora was related to the antecedent, i.e., the nearest element in relation to the Binding Theory.

Keywords: Binding Theory; Coreferential Processing; Anaphora.

\section{Introdução}

Uma das questões principais no estudo do processamento da linguagem humana é a resolução de referências. Na teoria sintática, sabe-se que a resolução de relações referenciais é afetada pela gramática via Teoria de Ligação (Binding Theory, CHOMSKY, 1981), a qual define as restrições sintáticas que permitem a identificação dos respectivos antecedentes gramaticais de anáforas, pronomes e expressões referenciais.

A Teoria de Ligação de Chomsky divide essas restrições em três princípios. 0 Princípio $\mathrm{A}$, que se refere à resolução correferencial das anáforas, tais como reflexivos e recíprocos, o Princípio B, que está relacionado com a resolução referencial de pronomes, e o Princípio C, que remete às expressões referenciais. Considerando a resolução correferencial de uma anáfora, o Princípio A, por exemplo, prediz que esse termo deve ser ligado por um antecedente em seu domínio de vinculação. Em relação aos pronomes, o Princípio B prediz que tal elemento precisa estar livre neste mesmo domínio.

Uma importante questão empírica que surge do estudo dos princípios de ligação é o modo como eles atuam durante o momento reflexo do processamento de sentenças. Em outras palavras, trata-se da maneira como os princípios, formalmente definidos e caracterizados em termos de um modelo mental de língua, interagem com os meios físicos que subjazem ao processamento linguístico online. Fatores ligados à memória operacional, ao custo de processamento das variadas formas de retomada anafórica e ao papel de diferentes traços formais e semânticos no estabelecimento das relações correferenciais possivelmente afetam a aplicação dos princípios no momento em que uma sentença é ouvida por um falante, e devem, por esta razão, serem investigados.

Uma maneira de se aprofundar nas questões daí decorrentes é investigar a possível influência de elementos sentenciais os quais ficam retidos na memória operacional quando a sentença é lida ou ouvida, e que podem, em etapas posteriores do 
processamento linguístico, atuar como antecedentes para elementos anafóricos que vão sendo identificados à medida em que a sentença é processada. No momento em que um elemento anafórico é reconhecido em uma dada configuração sintática, os princípios de ligação seriam acionados e buscariam na memória de trabalho os possíveis antecedentes com os quais os elementos anafóricos seriam vinculados. Se um elemento está dentro do escopo de atuação de um dado princípio, diz-se que ele é um antecedente disponível e, ao contrário, caso ele esteja fora desse escopo, será considerado um antecedente indisponível.

O objetivo dessa pesquisa é investigar a influência dos antecedentes disponíveis e indisponíveis no processamento das relações correferenciais estabelecidas pela anáfora "ele(a) mesmo(a)" por falantes nativos do português brasileiro (PB). Resultados de pesquisas como as de Nicol e Swinney (1989) e Clifton, Kennisson e Albrecht (1997), com dados do inglês, e de Oliveira, Leitão e Henrique (2012) e Oliveira, Leitão e Araújo (2013) para o português brasileiro, observaram apenas a influência de antecedentes disponíveis. Já estudos como os de Badecker e Straub (2002), Sturt (2003) e Kennisson (2003) apresentam resultados em que há a influência de antecedentes indisponíveis. Assim, o presente estudo pretende prover mais dados empíricos que possam ajudar dirimir a questão de saber se ambos os tipos de antecedentes, ou apenas um deles, influem no processamento correferencial.

O estudo experimental apresentado neste trabalho investigou o tempo de leitura da anáfora "ele(a) mesmo(a)" encontrado em sentenças que traziam um antecedente disponível e indisponível para a anáfora. Dividimos o termo "ele(a) mesmo(a)" em dois segmentos buscando verificar se o segmento "ele(a)" será analisado primeiramente como pronome, ficando livre em seu domínio de vinculação, de acordo com o Princípio B, ou se, com o aparecimento do segmento "mesmo(a)" haverá um reanálise, ficando “ele(a) mesmo(a)" ligado ao antecedente disponível à anáfora, indo a favor do Princípio A.

O trabalho está organizado da seguinte forma. Na seção seguinte, apresentam-se tanto o background teórico sobre o qual a pesquisa aqui mostrada se assenta, quanto uma resenha dos estudos anteriores, feitos com dados do inglês e do português brasileiro, a respeito da influência dos antecedentes disponíveis e indisponíveis no processamento anafórico. A seção 3 descreve o experimento realizado com vistas ao 
provimento de evidências empíricas sobre as questões aqui tratadas, com a seção 4 trazendo as conclusões finais.

\section{Fundamentação Teórica}

O Princípio A da Teoria da Ligação diz que uma anáfora deve ser ligada por um antecedente em seu domínio de vinculação, e que este antecedente deve c-comandar ${ }^{1}$ a anáfora. Tem-se por domínio da anáfora uma oração mínima que contém a anáfora e seu sujeito. Já o Princípio B afirma que os pronomes têm que estar livres em seu domínio de vinculação, ou seja, os pronomes devem estar ligados a um antecedente fora do seu domínio local. Por fim, o Princípio C contempla as expressões referenciais, predizendo que essas expressões devem ser livres, não podendo ser vinculadas a um antecedente.

Estudos como os de Nicol e Swinney (1989) observaram que apenas os antecedentes disponíveis estruturalmente influenciam a resolução da correferência em termos de processamento. Essa postulação é chamada de Filtro de Ligação Inicial, o qual exclui imediatamente os antecedentes indisponíveis na resolução da correferência. Para ilustrar o que foi dito acima, observamos o exemplo:

\section{(1) John thinks that Peter ${ }_{i}$ hates himself ${ }_{i}^{2}$}

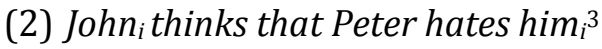

Levando em consideração a Hipótese do Filtro Inicial, o DP Peter em (1) é considerado como antecedente legítimo do reflexivo himself, de acordo do Princípio A da Teoria da Ligação. Já o DP John, que não é um antecedente acessível, é excluído nos primeiros estágios de processamento, não podendo, assim, ser considerado como antecedente legítimo.

Nicol e Swinney (1989) realizaram um experimento de priming cross modal ${ }^{4}$, no qual participantes ouviam as sentenças e logo após tinham que fazer uma decisão lexical para uma palavra sonda, mostrada visualmente, que surgia após pronomes e anáforas. Eles verificaram que a anáfora himself, segundo o Princípio A da Teoria da Ligação,

\footnotetext{
${ }^{1} \mathrm{C}$-comando $=\alpha$ c-comanda $\beta$ se e somente se $\beta$ é o irmão de $\alpha$ ou filho (ou neto, ou bisneto...) do irmão de

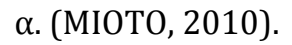

${ }^{2}$ João acha que Peter odeia ele mesmo.

${ }^{3}$ João acha que Peter odeia ele.

${ }^{4}$ Estímulos são apresentados auditivamente e sondas apresentadas visualmente.
} 
vinculou-se ao DP mais próximo, desconsiderando o mais distante. Com a substituição da anáfora himself pelo pronome him, como em (2), ocorreu o contrário. 0 pronome him permitiu a vinculação com o antecedente mais distante. Vale salientar que, nos exemplos com a anáfora himself, houve um efeito significativo de priming em relação aos antecedentes mais próximos; porém, não houve esse mesmo efeito significativo para os mais distantes. Já nos exemplos com o pronome him, os tempos de decisão lexical mostram um efeito priming significativo apenas para os DPs mais distantes.

Clifton, Kennison e Albrecht (1997) também elaboraram um estudo cujos resultados vão a favor à Teoria do Filtro de Ligação. Neste estudo, um experimento de leitura automonitorada foi elaborado e nele encontrou-se apenas a influência dos antecedentes disponíveis na resolução da correferência. Abaixo seguem exemplos das frases usadas nesse experimento:

(3) The supervisors paid him yesterday to finish typing the manuscript. ${ }^{5}$

(4) The supervisor paid him yesterday to finish typing the manuscript. ${ }^{6}$

(5) The supervisors paid his assistant to finish typing the manuscript. ${ }^{7}$

(6) The supervisor paid his assistant to finish typing the manuscript. ${ }^{8}$

Os resultados obtidos por Clifton et al. mostraram um efeito match/mismatch em (5) e (6), mas não em (3) e (4). Nas regiões imediatamente seguintes às palavras him/his, os tempos de leitura foram mais altos em (5), em relação às outras três condições. De acordo com os exemplos acima, pode-se concluir que tal estudo corrobora a Teoria do Filtro de Ligação. 0 filtro inicial atuou significativamente no processamento das sentenças.

Por outro lado, estudos como os de Badecker e Straub (2002) vão, em parte, contra o modelo da Teoria do Filtro de Ligação. Nesse estudo, foi elaborado um experimento de leitura automonitorada e nele foi apresentado um conjunto inicial de antecedentes que abrangiam entidades discursivas estruturalmente disponíveis e indisponíveis. Nesse experimento foi manipulado o gênero dos antecedentes disponíveis e indisponíveis, e os resultados apontaram que, quando os antecedentes indisponíveis e disponíveis concordavam com o gênero do reflexivo, havia retardos no tempo de leitura;

\footnotetext{
${ }^{5}$ Os supervisores o pagaram ontem para terminar a datilografia do manuscrito.

${ }^{6} 0$ supervisor o pagou ontem para terminar a datilografia do manuscrito.

${ }^{7}$ Os supervisores pagaram o assistente dele para terminar a datilografia do manuscrito.

${ }^{8} \mathrm{O}$ supervisor pagou o assistente dele para terminar a datilografia do manuscrito.
} 
porém, quando o gênero do reflexivo combinava com o antecedente disponível, o tempo de leitura era mais rápido. Isso significa que os antecedentes indisponíveis influenciaram no tempo de leitura das sentenças.

Sturt (2003) também investigou a correferência dos antecedentes disponíveis e indisponíveis por meio da técnica experimental de eye tracking 9 . Controlando a disponibilidade dos antecedentes bem como a concordância de gênero entre esses antecedentes e as suas respectivas retomadas, Sturt elaborou frases experimentais como as seguintes:

(7) Jonathan was pretty worried at the City Hospital. He remembered that the surgeon had pricked himself with a used syringe needle. There should be an investigation soon ${ }^{10}$.

(8) Jennifer was pretty worried at the City Hospital. She remembered that the surgeon had pricked himself with a used syringe needle. There should be an investigation soon ${ }^{11}$.

(9) Jonathan was pretty worried at the City Hospital. He remembered that the surgeon had pricked herself with a used syringe needle. There should be an investigation soon ${ }^{12}$.

(10) Jennifer was pretty worried at the City Hospital. She remembered that the surgeon had pricked herself with a used syringe needle. There should be an investigation soon ${ }^{13}$.

Podemos observar que, mesmo o primeiro nome (Jennifer/Jonathan) estando no foco discursivo, ele não é um antecedente disponível para o reflexivo, de acordo com a Teoria da Ligação. Já o segundo nome (the surgeon) é considerado por Sturt como um antecedente possível. Sturt (2003) salienta que o tempo de leitura na primeira fixação e na primeira sacada foi mais rápido quando o gênero da anáfora combinava com o gênero antecedente disponível, diferentemente de quando o gênero da anáfora não combinava. Os resultados deste experimento indicaram que o processamento correferencial foi tardio, mostrando a influência do antecedente indisponível.

Os estudos de Sturt (2003) concluem que o processamento da correferência ocorre em dois estágios: o primeiro seria a ligação das anáforas e seus antecedentes, e o

\footnotetext{
${ }^{9}$ Rastreamento ocular.

${ }^{10}$ Jonathan estava muito preocupado no Hospital da Cidade. Ele lembrou que o cirurgião tinha picado ele mesmo com uma agulha de seringa usada. Deveria haver uma investigação em breve.

${ }^{11}$ Jennifer estava muito preocupada no Hospital da Cidade. Ela lembrou que o cirurgião tinha picado ele mesmo com uma agulha de seringa usada. Deveria haver uma investigação em breve.

12 Jonathan estava muito preocupado no Hospital da Cidade. Ele lembrou que o cirurgião tinha picado ela mesma com uma agulha de seringa usada. Deveria haver uma investigação em breve.

13 Jennifer estava muito preocupada no Hospital da Cidade. Ela lembrou que o cirurgião tinha picado ela mesma com uma agulha de seringa usada. Deveria haver uma investigação em breve.
} 
segundo seria a influência dos antecedentes indisponíveis, controlado por aspectos semântico-discursivos.

Kennison (2003) também observou a influência dos antecedentes indisponíveis na resolução da correferência. Através da leitura automonitorada, percebeu-se que o sintagma nominal de sujeito indisponível em uma sentença influenciou o processamento de pronomes quando não havia um antecedente disponível. Além disso, Kennison (2003), assim como Sturt (2003), identificou dois estágios de processamento. No primeiro, o Princípio B bloqueou os antecedentes não-disponíveis, e no segundo estágio, os antecedentes indisponíveis interferiram no processamento quando não havia um antecedente disponível. Dessa forma, no primeiro estágio, haveria a formação de um conjunto de possíveis antecedentes disponíveis ou não-disponíveis, e, no segundo estágio, seria feita a ligação entre os possíveis antecedentes e o pronome, podendo haver influência dos traços de gênero e número.

A questão do processamento correferencial também foi investigada em português brasileiro (PB). Em uma série de experimentos com falantes dessa língua, buscaram-se evidências empíricas sobre o modo como são processadas anáforas e pronomes. Estes estudos obtiveram resultados interessantes acerca dos fatores envolvidos no processamento de tais elementos.

Leitão, Peixoto e Santos (2008) analisaram o processamento da correferência com falantes do português brasileiro, bem como a atuação dos princípios de ligação nesse processo. Eles produziram dois experimentos, tendo em posição de objeto na sentença o pronome "ele". Foram controlados os traços de gênero, assim como o de número e animacidade dos antecedentes. No primeiro experimento, observou-se o bloqueio gerado pelo Princípio B na vinculação entre o pronome na posição de objeto e o sujeito respectivo. No segundo experimento, uma continuidade do primeiro, o que difere é a ocorrência de um preâmbulo em que há um antecedente disponível ao pronome que combinava os mesmos traços. Leitão, Peixoto e Santos (2008) destacam que, neste experimento, mesmo com a presença de um antecedente disponível ao pronome "ele", a leitura foi mais demorada que no primeiro experimento. Estes resultados evidenciam, então, que, com a vinculação do pronome ao antecedente disponível, a busca por um antecedente terminou rapidamente, sem a interferência dos traços de gênero, número e 
animacidade dos antecedentes indisponíveis, a tempo de influenciar na resolução da correferência.

Em outro estudo, Oliveira, Leitão e Henrique (2012) elaboraram um experimento que buscou investigar o processamento da anáfora "a si mesmo(a)" sob a influência do Principio A da Teoria da Ligação na resolução de correferências. Através da técnica experimental de leitura automonitorada, após a qual havia uma medida offline constituída por uma pergunta-controle, o trabalho buscou mostrar que os reflexivos podem ser lidos mais rapidamente nas sentenças em que o gênero da retomada concorda com o gênero do antecedente disponível. Os resultados mostraram que a anáfora se vincula ao antecedente mais próximo, desprezando o mais distante, indo, assim, a favor do Filtro de Ligação Inicial. De acordo com os resultados obtidos, Oliveira, Leitão e Henrique (2012) destacaram que, nas condições em que o gênero da retomada (anáfora) era idêntico ao gênero do antecedente mais próximo, os tempos de leitura do segmento crítico, no caso, o segmento que continha a anáfora "a si mesmo(a)", foram significativamente menores do que em comparação às demais condições. Neste experimento, observou-se também um efeito spill over ${ }^{14}$, uma vez que os tempos de leitura do segmento seguinte ao crítico seguiram o mesmo padrão do segmento crítico. Os tempos de leitura do segmento pós-crítico também foram mais rápidos nas condições em que o gênero da retomada era idêntico ao gênero do antecedente disponível.

Além da análise dos tempos de leitura do segmento crítico e do segmento póscrítico, Oliveira, Leitão e Henrique (2012) verificaram, através de medidas offline, os índices de respostas (SIM/NÃO) às perguntas-controle de cada condição. Os resultados das respostas corroboram os resultados obtidos através do experimento online, ou seja, mostraram que os antecedentes indisponíveis foram excluídos no processamento da anáfora. Isso ressalta a influência do Principio A da Teoria da Ligação no processamento correferencial.

A conclusão dos resultados obtidos por Oliveira, Leitão e Henrique (2012) é que apenas os antecedentes disponíveis influenciaram a resolução da correferência, conforme o postulado de Nicol e Swinney (1989). Isto quer dizer que os antecedentes indisponíveis são excluídos imediatamente nos primeiros estágios de processamento.

\footnotetext{
${ }^{14}$ Oliveira, Leitão e Henrique (2012): spill over - ocorre quando um efeito esperado para um segmento (x) pode se expressar no segmento (y) seguinte.
} 
Já Oliveira, Leitão e Araújo (2013) analisaram a resolução da correferência da anáfora "ele(a) mesmo(a)". A partir de um experimento de leitura automonitorada, os autores investigaram o tempo de leitura da anáfora "ele(a) mesmo(a)" dentro do escopo da sentença, em frases que possuíam tanto um antecedente disponível estruturalmente quanto um indisponível em termos da Teoria da Ligação. Este experimento foi feito com base no experimento realizado por Oliveira, Leitão e Henrique (2012), adaptando a anáfora "a si mesmo(a)" para o termo anafórico "ele(a) mesmo(a)". 0 objetivo por hora proposto era verificar se haveria alguma influência do traço pronominal "ele(a)" contido na expressão anafórica “ele(a) mesmo(a)”.

Os resultados obtidos no experimento de Oliveira, Leitão e Araújo (2013) corroboraram os resultados obtidos por Oliveira, Leitão e Henrique (2012), ou seja, apenas os antecedentes disponíveis estruturalmente influenciaram a resolução correferencial da anáfora, segundo o Princípio A da Teoria da Ligação. Comparando esses dois experimentos, um com a anáfora "a si mesmo(a)" e outro com "ele(a) mesmo(a)", a única diferença encontrada diz respeito a medidas offline, as quais, no caso do experimento com o termo anafórico "ele(a) mesmo(a)" sugeriram alguma influência do traço pronominal.

A partir do que foi apresentado anteriormente, podemos concluir que os resultados obtidos neste experimento, assim como os resultados obtidos por Oliveira, Leitão e Henrique (2012) com a anáfora “a si mesmo(a)", corroboram a Hipótese do Filtro de Ligação, que prediz que os antecedentes indisponíveis são imediatamente excluídos na resolução da correferência.

A partir do estudo de Oliveira, Leitão e Araújo (2013), adaptamos o experimento com a anáfora "ele(a) mesmo(a)" segmentando este termo com o intuito de medir a resolução correferencial do segmento "ele(a)" e do segmento "mesmo(a)". Assim, como no experimento de Oliveira, Leitão e Araújo (2013) em que o termo anafórico foi medido em um único segmento, pretendeu-se observar se o traço [+pronominal] do "ele(a)" influenciaria na resolução da correferência, vinculando-se primeiramente aos antecedentes disponíveis para os pronomes, como salienta o Princípio B da Teoria da Ligação ou se, ao chegar no segmento seguinte, "mesmo(a)", haveria uma reanálise, vinculando-se aos antecedentes disponíveis estruturalmente às anáforas, conforme o Princípio A da mesma teoria. 


\section{0 experimento}

O objetivo do experimento aqui relatado é verificar o processamento da anáfora "ele(a) mesmo(a)" quando segmentada dentro do escopo sentencial. Investigamos a atuação tanto do Princípio B da Teoria da Ligação, o qual ocorreria quando do processamento do primeiro elemento, no caso, "ele(a)", quanto do Princípio A, o qual ocorreria quando do processamento do segundo elemento, o termo anafórico "mesmo(a)". Investiga-se, ainda, o papel dos traços de gênero no estabelecimento da disponibilidade dos antecedentes, e o quanto esse fator pode influir no processamento das relações correferenciais no escopo sentencial. Exemplificando o que descrevemos acima, observemos as sentenças abaixo:

a) Joana lembrou que Fábio picou ele mesmo com a agulha de costura.

b) Joana lembrou que Fábio picou ela mesma com a agulha de costura.

No exemplo (a) o DP Fábio é o antecedente disponível da anáfora “ele(a)mesmo(a)", pois está dentro do seu domínio de vinculação. Já o DP Joana corresponde ao antecedente indisponível à anáfora, pois está fora do seu domínio de vinculação. É notório que em (a) o gênero do termo anafórico corresponde ao antecedente disponível, já em (b) o gênero da anáfora corresponde ao antecedente indisponível. Neste caso, um falante de PB poderá ligar o pronome "ela" ao antecedente mais distante, indo a favor do que prediz o Princípio B, e quando aparecer o segmento "mesmo(a)", terá que fazer uma reanálise, ligando-o ao antecedente mais próximo, conforme o Princípio A, elevando assim o tempo de leitura, pois o gênero da retomada não combina com o gênero do antecedente mais próximo.

c) Fábio lembrou que Edu picou ele mesmo com a agulha de costura.

No exemplo (c) acima, observamos algo diferente. 0 antecedente disponível e o indisponível combinam em gênero com a anáfora "ele(a) mesmo(a)". Aqui, podemos verificar, através dos experimentos, se o antecedente indisponível irá influenciar ou não 
na resolução da correferência, indo de acordo com o Princípio A, vinculando-se ao DP Edu ou indo de acordo com o Princípio B, ligando-se ao DP Fábio.

Nessa perspectiva, elaboramos o nosso experimento utilizando a técnica de leitura automonitorada. Nas sentenças, temos como variáveis independentes o gênero dos antecedentes disponíveis, o gênero dos antecedentes indisponíveis e o gênero da retomada. Nas variáveis dependentes temos as medidas online do tempo de leitura do primeiro segmento crítico "ele(a)", com o objetivo de verificar o seu traço [+pronominal] e do segundo segmento crítico "mesmo(a)", com o objetivo de verificar se o sujeito irá fazer uma reanálise, ligando o termo anafórico ao antecedente disponível à anáfora. Além das medidas online, temos ainda como variável dependente os índices de respostas SIM e NÃO após uma pergunta feita final da sentença.

A partir dessas variáveis dependentes e independentes, temos seis condições experimentais apresentadas abaixo:

(1) Antecedente indisponível feminino (F), disponível masculino (M) e retomada masculino (RM).

FMRM. Joana lembrou que Fábio picou ele mesmo com a agulha de costura. Fábio se picou?

(2) Antecedente indisponível masculino (M), disponível feminino (F) e retomada masculino (RM).

MFRM. Fábio lembrou que Joana picou ele mesmo com a agulha de costura. Fábio se picou?

(3) Antecedente indisponível feminino (F), disponível masculino (M) e retomada feminino (RF). se picou?

FMRF. Joana lembrou que Fábio picou ela mesma com a agulha de costura. Joana

(4) Antecedente indisponível masculino (M), disponível feminino (F) e retomada feminino (RF).

MFRF. Fábio lembrou que Joana picou ela mesma com a agulha de costura. Joana se picou?

(5) Antecedente indisponível masculino (M), disponível masculino (M) e retomada masculino (RM).

MMRM. Fábio lembrou que Edu picou ele mesmo com a agulha de costura. Edu se picou?

(6) Antecedente indisponível feminino (F), disponível feminino (F) e retomada feminino (RF). picou?

FFRF. Joana lembrou que Laís picou ela mesma com a agulha de costura. Laís se 
Manipulamos no experimento o gênero dos antecedentes disponíveis das sentenças testadas, o gênero dos antecedentes indisponíveis e o gênero da retomada com o objetivo de verificar a relação da localidade da anáfora "ele(a) mesmo(a)". Nas perguntas lidas após a sentença, destacamos o antecedente que apresentava o gênero semelhante ao da retomada, como podemos observar nas sentenças (1), (2), (3) e (4). Nas sentenças (5) e (6) o gênero do antecedente disponível e indisponível concordam com o gênero da retomada. Neste caso, a pergunta é feita destacando o antecedente disponível da anáfora.

\subsection{Método}

Participantes

Participaram do experimento um grupo de dezoito alunos de graduação da Universidade Federal da Paraíba. Todos são falantes nativos do português brasileiro, apresentando idades entre vinte e cinquenta anos.

\section{Material}

O material constitui de setenta e duas frases experimentais, sendo vinte e quatro conjuntos de frases experimentais distribuídas em seis condições e intercaladas por quarenta e oito frases distratoras. Cada participante foi exposto às frases experimentais desenvolvidas através do design experimental em quadrado latino a fim de que cada um tivesse acesso a todas as condições experimentais. Cada frase que aparecia na tela do computador era seguida de uma pergunta de compreensão que solicita a resposta SIM ou NÃO aos voluntários. Vale salientar que as frases experimentais foram divididas em dez segmentos, sendo o segmento seis (ele) e sete (mesmo) os segmentos críticos.

\section{Procedimento}

O experimento foi elaborado por meio do programa Psyscope. A técnica experimental utilizada foi a de Leitura Automonitorada, na qual o participante tem o 
total controle do seu ritmo de leitura em frente a tela do computador. 0 experimento em questão foi desenvolvido no laboratório de Psicolinguística (LAPROL), situado na Universidade Federal da Paraíba, permitindo aos participantes voluntários total concentração.

A tarefa resume-se na leitura natural de frases divididas em dez segmentos, seguidas por uma pergunta de compreensão, obrigando ao participante escolher como resposta "sim" ou "não", conforme ilustrado abaixo:

d) Maria / disse / que / João / machucou / ele / mesmo / no / parque/ de diversão./ João se machucou?

Os participantes sentaram-se em frente à tela do computador e leram as instruções do experimento. Nessas instruções, o participante era informado que na tela apareceriam frases segmentadas e em seguida uma pergunta de interpretação relacionada às frases lidas. Depois de ler as instruções, os participantes passaram por um teste prático a fim de habituá-los com o experimento. Todos os participantes foram instruídos a ler com atenção e da maneira mais natural possível. Para dar início ao experimento, o participante apertava a tecla $\mathrm{L}$ do teclado a sua frente para começar a leitura do primeiro segmento, que no caso do exemplo (d) acima seria o DP "Maria". Para dar continuidade à leitura dos próximos segmentos, os participantes deveriam pressionar a tecla L novamente até o último segmento que, segundo (d) seria "diversão". Após a leitura da última palavra da sentença, os participantes deveriam pressionar a tecla L mais uma vez e uma pergunta interpretativa sobre a sentença lida apareceria na tela do computador. Se a resposta de pergunta fosse 'SIM', o participante pressionaria a tecla 'SIM' do computador. Se a resposta fosse 'NÃO', pressionaria a tecla 'NÃO'. As perguntas de compreensão se referiam ao antecedente que possuía o gênero concordando com a retomada (anáfora). No caso das frases em que o gênero da retomada concordava com os dois antecedentes, a pergunta se referia ao antecedente mais próximo da retomada.

Neste experimento, tanto os tempos de leitura dos dez segmentos das frases quanto o número de respostas 'SIM' ou 'NÃO' foram gravados, e, a partir desses dados foram feitas as estatísticas e elaborado os resultados deste experimento. É o que veremos a seguir. 


\subsection{Resultados e Discussão}

Aqui neste item, iremos expor os dados obtidos e a partir destes confirmar ou não a nossa hipótese de que o sujeito, ao ler a sentença e ao chegar ao segmento 6, "ele(a)", aplicará o Princípio B. Com o surgimento do segmento seguinte, "mesmo(a)", o sujeito irá fazer uma reanálise, ficando "ele(a) mesmo(a)" e assim, aplicará o Princípio A da Teoria da Ligação.

Através da variância ANOVA podemos observar que não ocorreu um efeito principal da variável gênero do antecedente disponível $F(5,84)=2,56 \mathrm{p}=0,08$, gênero do indisponível $F(5,84)=2,37 p=0,12$ e gênero da retomada $F(5,84)=0,11 p=0,73$. Esses resultados corroboram com os resultados encontrados por Oliveira, Leitão e Henrique (2012). Observamos também que não houve efeito de interação da variável de gênero do antecedente disponível e gênero do antecedente indisponível $F(5,84)=1,80$ $p=0,11$, gênero do antecedente disponível e gênero da retomada $F(5,84)=1,71 p=$ 0,15, e efeito de interação da variável gênero do antecedente indisponível e gênero da retomada $F(5,84)=1,61 p=0,18$, indo contra os resultados obtidos por Oliveira, Leitão e Henrique (2012).

Gráfico 1: Segmento 6 ("ele")

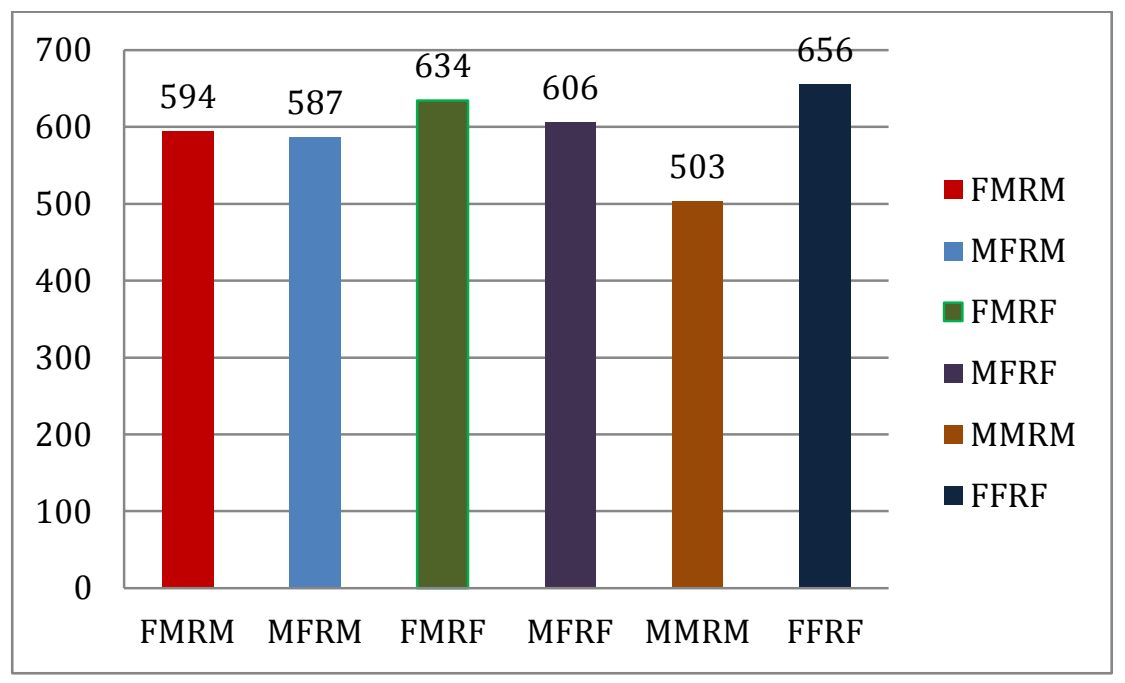

A partir do gráfico, podemos observar que nas condições em que o gênero do antecedente indisponível combinava com o gênero da retomada, o tempo de leitura foi 
maior, exceto na condição MFRM. Esses resultados são mostrados por meio dos testes t apresentados a seguir.

Nas condições, MMRM e FMRM, os resultados foram significativos: $t(18)=-2,27$ $\mathrm{p}<0,03$. Porém, na interação entre as condições FFRF e MFRF t $(18)=0,81 \mathrm{p}=0,42$, MFRF e FMRF $t(18)=-0,67 p=0,50$ e FMRM e MFRM t $(18)=0,16 p=0,87$ não encontramos resultados significativos.

Através do que foi exposto, esperávamos que o sujeito, ao chegar ao segmento 6, ligasse o pronome ao antecedente indisponível, porém isso não se refletiu aqui. Ou seja, o Princípio B não foi encontrado a tempo neste segmento.

No segmento 7 "mesmo(a)", podemos observar que houve efeito principal do gênero do antecedente disponível $\mathrm{F}(5,84)=4,66 \mathrm{p}=0,01$ e do gênero do antecedente indisponível $\mathrm{F}(5,84)=6,10 \mathrm{p}=0,01$.

Podemos notar também que houve efeito de interação da variável gênero do antecedente disponível e indisponível $\mathrm{F}(5,84)=3,03 \mathrm{p}<0,01$, assim como houve efeito de interação da variável gênero do antecedente disponível e retomada $F(5,84)=3,54 p$ $<0,009$. Observamos um efeito de interação das variáveis gênero dos antecedentes (disponível e indisponível) e retomada $F(5,84)=2,54 \mathrm{p}<0,01$. Porém, a interação entre o gênero do antecedente indisponível e retomada apresentaram resultados não significativos $F(5,84)=1,88 \mathrm{p}=0,13$.

Gráfico 2: Segmento 7 ("mesmo")

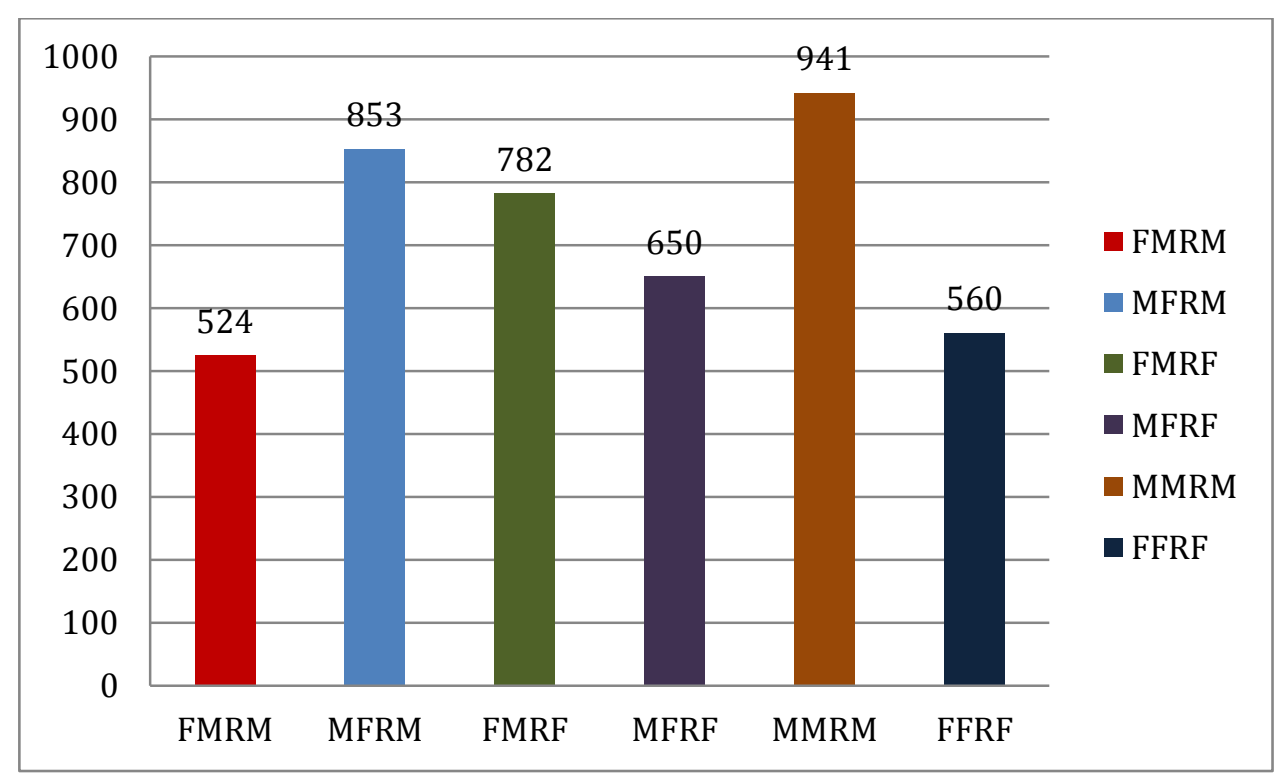


Entre as condições MMRM e FMRM, encontramos um efeito de interação, explicitado pelo teste $t(18)=3,28 \mathrm{p}<0,003$. Um efeito de interação também pode ser visto entre as condições FMRM E MFRM t (18) = -2,99 p < 0,007. Já nas condições, MFRF e FMRF, $t(18)=-1,46 p=0,15$ e FFRF e MFRF $t(18)=-1,44 p=0,16$, não encontramos um efeito de interação.

A partir dos dados, podemos concluir que o segmento 7 foi relacionado ao antecedente disponível corroborando assim com o Princípio A. Esse resultado foi semelhante ao que foi encontrado no experimento de Oliveira, Leitão e Henrique (2012) que trata da anáfora "a si mesmo(a)" e ainda, semelhante ao resultado encontrado no experimento de Oliveira, Leitão e Araújo (2012) sobre a anáfora “ele(a) mesmo(a)" medido no mesmo segmento.

É no segmento 7, "mesmo(a)", que se tem a completude da expressão anafórica “ele(a) mesmo(a)" e a confirmação de que a leitura desta expressão pelo sujeito é vista como uma anáfora.

Através do gráfico podemos observar que as condições em que o antecedente disponível combinava com o gênero da retomada, MFRF e FMRM, o tempo de leitura foi mais rápido do que quando o gênero da retomada não combinava com o gênero do disponível, FMRF e MFRM. No entanto, nas condições MMRM e o FMRM, o resultado do teste t dá significativo. Ou seja, quando o antecedente disponível e indisponível combina com o gênero da retomada (MMRM), o tempo de leitura foi maior do que quando apenas o gênero do antecedente disponível combina com o gênero da retomada (FMRM).

Além das medidas online do tempo de leitura dos segmentos 6 e 7 da expressão anafórica "ele(a) mesmo(a)", medimos de forma offline os índices de resposta, SIM ou NÃO, das perguntas que surgiam posteriormente aos fragmentos das frases experimentais. 0 foco dessas perguntas das condições FMRM, MFRM, FMRF e MFRF eram no antecedente que combinava com o gênero da retomada, sendo esse antecedente disponível ou indisponível. Já nas condições em que tanto o gênero do antecedente disponível e indisponível combinavam com o gênero da retomada, MMRM e FFRF, a pergunta focalizava apenas o antecedente disponível estruturalmente.

Podemos verificar os resultados a seguir: 
Tabela 1 - Índices de resposta das perguntas

\begin{tabular}{|c|c|c|}
\hline Condição & Tecla & Número \\
\hline \multirow{2}{*}{$\begin{array}{c}\text { FMRM } \\
\mathrm{X}^{2}=55,04 \text { e } \mathrm{p}<0,01\end{array}$} & Sim & 76 \\
\hline & Não & 8 \\
\hline \multirow{2}{*}{$\begin{array}{c}\text { MFRM } \\
\mathrm{X}^{2}=2,33 \text { e } \mathrm{p}<0,12\end{array}$} & Sim & 35 \\
\hline & Não & 49 \\
\hline \multirow{2}{*}{$\begin{array}{c}\text { FMRF } \\
\mathrm{X}^{2}=6,48 \text { e } \mathrm{p}<0,08\end{array}$} & Sim & 34 \\
\hline & Não & 50 \\
\hline \multirow{2}{*}{$\begin{array}{c}\text { MFRF } \\
X^{2}=58,3 \text { e } p<0,002\end{array}$} & Sim & 77 \\
\hline & Não & 7 \\
\hline \multirow{2}{*}{$\begin{array}{c}\text { MMRM } \\
\mathrm{X}^{2}=34,71 \text { e } \mathrm{p}<0,003\end{array}$} & Sim & 69 \\
\hline & Não & 15 \\
\hline \multirow{2}{*}{$\begin{array}{c}\text { FFRF } \\
\mathrm{X}^{2}=32,19 \text { e } \mathrm{p}<0,001\end{array}$} & Sim & 68 \\
\hline & Não & 16 \\
\hline
\end{tabular}

Observando os dados da tabela acima, notamos que nas condições em que o gênero do disponível concorda com o gênero da retomada, FMRM e MFRF, o índice de SIM foi mais alto do que em relação ao NÃO.

$\mathrm{Na}$ condição em que o gênero do antecedente indisponível concorda com o gênero da retomada, MFRM e FMRF, o número de NÃO foi superior ao número de SIM. Já nas condições em que tanto os antecedentes disponíveis quanto os antecedentes indisponíveis combinam com o gênero da retomada os índices de SIM foi bem maior do que os de NÃO, tendo em vista que o foco do gênero na pergunta foi dado ao antecedente disponível.

Através dos números, podemos notar que os resultados obtidos na medida offline corroboram com os resultados obtidos online. Ou seja, a atuação do Princípio A da Teoria da Ligação se confirma, mostrando que o sujeito elimina em primeiro estágio os antecedentes indisponíveis.

Fazendo uma ligação entre o experimento elaborado por Oliveira, Leitão e Henrique (2012) com a anáfora "a si mesmo(a)", o experimento elaborado por Oliveira, Leitão e Araújo (2013) com a anáfora "ele(a) mesmo(a)" em um mesmo segmento e 
ainda com este experimento - anáfora "ele(a) mesmo(a)" em segmentos diferentes podemos observar que os resultados possuem uma certa concordância, diferenciando apenas na medida offline feita por Oliveira, Leitão e Araújo (2013) na condição MFRM e na medida online feita por Oliveira et al. (2012) em que se mede o efeito de interação do segmento 6 da variável de gênero do antecedente disponível e gênero do antecedente indisponível; gênero do antecedente disponível e gênero da retomada; e efeito de interação da variável gênero do antecedente indisponível e gênero da retomada.

\section{Considerações finais}

Levando em consideração alguns estudos que refletem sobre os antecedentes disponíveis e indisponíveis na resolução da correferência, alguns estudiosos como Nicol e Swinney (1989) mostram que os antecedentes disponíveis influenciam na hora do processamento das anáforas, desconsiderando assim os antecedentes indisponíveis (Filtro de Ligação Inicial). Badecker e Straub (2002), afirmam que os antecedentes indisponíveis influenciam no tempo de leitura das sentenças. Já Sturt (2003), por exemplo, conclui em seu estudo que o processamento correferencial do antecedente indisponível foi tardio, mostrando também a influência do antecedente indisponível.

A partir desses estudos, o nosso experimento objetivou investigar a atuação dos Princípios A e B da Teoria da Ligação na expressão anafórica “ele(a) mesmo(a)" a fim de observar se os antecedentes disponíveis e indisponíveis influenciam na resolução da correferência.

Aqui, podemos observar através dos resultados obtidos que o Princípio A da Teoria da Ligação influencia na resolução da correferência. Ou seja, os antecedentes indisponíveis não são levados em consideração mesmo com a expressão anafórica segmentada. 0 sujeito ao chegar ao segmento 6, "ele(a)", não faz a ligação com o antecedente indisponível e, com o surgimento do segmento seguinte, mesmo(a), ele aplica o Princípio A, fazendo a eliminação em primeiro estágio do antecedente indisponível, como mostra a Teoria do Filtro de Ligação Inicial, de Nicol e Swinney (1989). Esses resultados obtidos aqui vão contra aos resultados encontrados por Badecker e Straub (2002) e Sturt (2003), Kennison (2003) e Leitão et al. (2008), que mostram a influência dos antecedentes indisponíveis na resolução da correferência. Os 
resultados obtidos nesse experimento vão de encontro aos que foram encontrados por Oliveira, Leitão e Henrique (2012) com a anáfora "a si mesmo(a)" e Oliveira, Leitão e Araújo (2013) com anáfora "ele(a) mesmo(a)".

Dessa forma, a questão da influência dos antecedentes disponíveis e indisponíveis sobre o processamento das anáforas ainda permanece sem uma resolução definitiva. Os resultados obtidos nos experimentos aqui relatados, e também em uma literatura relativamente ampla sobre o assunto, dividem-se em dois grupos opostos, um com dados que evidenciam essa influência, e outros com dados que parecem sustentar uma visão oposta. Esse estado de coisas aponta para a necessidade de se continuar a investigação sobre o processamento anafórico, como forma de compreender melhor como esse tipo de relação é processada.

O mesmo talvez se diga sobre o papel dos princípios de ligação no processamento de retomadas anafóricas. Conforme o afirmado anteriormente, o modelo teórico que sustenta o funcionamento desses princípios é elaborado muitas vezes sem observar como se dá sua interação com o aparato processador da linguagem, o que acaba por deixar algumas (interessantes) questões fora de alçada. Nesse sentido, o experimento aqui desenvolvido, antes de oferecer uma resposta categórica, termina por ao menos ilustrar algumas dessas questões. No geral, é possível sustentar a ideia de que os princípios agem tão logo o elemento anafórico é processado e, sendo um dado princípio acionado, como o Princípio A, no nosso caso, outros princípios passíveis de atuarem são de algum modo bloqueados, e uma reanálise esperada não acontece. Isso aponta para a existência de uma relação entre princípios formais e aparato processador mais estreita do que normalmente se supõe, mas que ainda requer mais estudos e maior aprofundamento, para que seja mais claramente caracterizada.

\section{Referências}

BADECKER, W.; STRAUB, K. The processing role of structural constraints on the interpretation of pronouns and anaphors. Journal of Experimental Psychology: Learning, Memory, and Cognition, v. 28, n. 4, p. 748-769, 2002.

CHOMSKY, N. Lectures on government and binding. Dordrecht: Foris, 1981. 
CLIFTON, C.; KENNISON, S. M.; ALBRECHT, J. E. Reading the Words Her, His, Him: Implications for Parsing Principles Based on Frequency and on Structure. Journal of Memory and language, v. 36, n. 17, p. 246-292, 1997.

KENNISON, S. Comprehending the pronouns her, him, and his: implications for theories of referential processing. Journal of Memory and Language, 2003.

LEITÃO, M.; PEIXOTO, P.; SANTOS, S. Processamento da correferência intra-sentencial em português brasileiro. Veredas on-line, n. 2, p. 50- 61, 2008.

MIOTO, C.; SILVA, M. C.; VASCONCELlOS, R. Novo Manual de Sintaxe. Florianópolis: Insular, 4. ed., 2010.

NICOL, J.; SWINNEY, D. The role of structure in coreference assignment during sentence comprehension. Journal of Psycholinguistic Research, v. 18, n. 1, p. 5-20, 1989.

OLIVEIRA, R.; LEITÃO, M. M.; HENRIQUE, J. A Influência dos Antecedentes Vinculados e não vinculados no processamento da anáfora "a si mesmo(a)". Linguística, v. 8, n. 2, 2012, p. 115-134. ISSN Versão Digital: 2238-975-X | ISSN Versão Impressa: 1808-835-X.

OLIVEIRA, R.; LEITÃO, M. M.; ARAÚJO, E. A Influência dos Antecedentes Vinculados e não vinculados no processamento da anáfora "ele(a) mesmo(a)". Revista do GELNE, Grupo de Estudos Linguísticos do Nordeste, v. 5, n. 1 e 2, Natal: UFRN, 2013, p. 115-134. ISSN Versão Digital: 2236-0883 | ISSN Versão Impressa: 1517-7874.

RAPOSO, E. P. Teoria da Gramática. A Faculdade da Linguagem. Editorial Caminho, SA, Lisboa, 1992.

STURT, P. The time-course of the application of binding constraints in reference resolution. Journal of Memory and Language, v. 48, p. 542-562, 2003.

Recebido em março de 2014.

Aceito em maio de 2014. 